\title{
Ocean researchers dive to deep-sea stations
}

\section{Colin Macilwain, Washington}

Fixed seafloor observatories are likely to replace traditional sea-going expeditions aboard research vessels as the dominant source of oceanographic data, leading researchers say. And the US government is starting to make plans for a comprehensive network of such observatories, to give oceanographers as exciting a range of research options as possible.

Oceanographers are increasingly aware of the limitations of their research ship expeditions for data gathering. "They have been very good for things with a very long lead time, such as plate tectonics," says Marcia McNutt, president of the Monterey Bay Aquarium Research Institute and of the American Geophysical Union. "But everything else is characterized by an event, and in expedition mode oceanographers cannot always be in the right place at the right time to collect data. So everyone agrees that observatories are the way to go."

It has been harder, however, to agree on what types of observatories would be most useful, where to put them, who should build and maintain them, and how they can be paid for without overstretching limited research budgets for oceanography.

But late last month, a report to the National Science Foundation (NSF) from the National Research Council (NRC), the operating branch of the National Academy of Sciences, set out a plan of how the problem should be approached. The report, the result of an NRC panel chaired by William Ryan of the Lamont-Doherty Earth Observatory in New York state, proposes that the NSF should plan and build such a system. The recommendation is likely to provide the basis for concrete plans from the NSF and other agencies, which will perhaps be announced next February as part of the 2002 budget.

\section{A first step}

The Ryan panel doesn't specify exactly what the network should be, but sets out the main parameters for its construction. "We don't yet have a perfect model, but the NRC report is an important first step," says McNutt, who wasn't on the NRC panel but attended a January workshop in Florida that provided much of the basis for its work.

The report says the network should be flexible and dynamic. It should incorporate some seafloor observatories connected to subsea cables and others with links to fixed buoys on the surface. In addition, rapidly deployable buoys would monitor oceanographic events, from algal blooms to volcanic eruptions. Other suggestions include new grant mechanisms to support very long-term work, open access to all data and an emphasis on standardization, to widen the usefulness

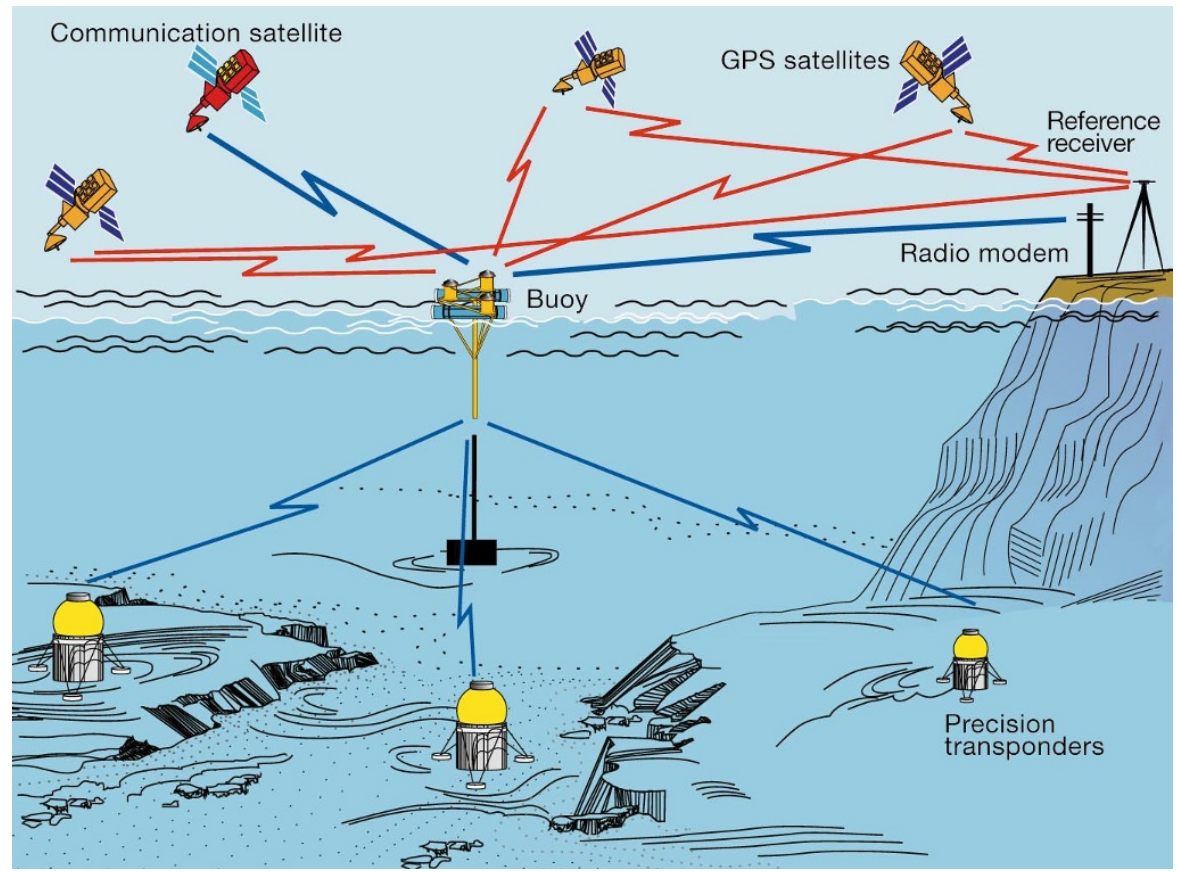

Ocean mission of the future: subsea observatories can send data to shore via buoys and satellites.

of both equipment and data. And it says the NSF should press ahead with its network, without waiting for international agreement on what such a global network should be like.

The panel wasn't asked to look at costs in detail, but it warns that the network will cost "approaching hundreds of millions of dollars" to build and tens of millions of dollars annually to maintain and operate. Oceanographers are confident that the other main agencies in ocean science - the National Oceanic and Atmospheric Administration (NOAA) and the US Navy - will become involved, but say the onus is on the NSF to get the project moving. The NSF's ocean research division is set to use the report to request $\$ 120$ million from its Major Research Equipment fund, spread over four or five years agency officials confirm.

CORE, the ocean research lobby group energetically led by Admiral James Watkins, a respected former energy secretary, has helped to build strong support for oceanography in the Congress, where the proposal is likely to be well received. "There's a definite raising of awareness of ocean science," says one congressional staffer.

Most existing seafloor observatories have been built by geophysicists or physical oceanographers. Geophysicists need a lot of communications bandwidth, but not much power for their sensors, and prefer their observatories to be linked by fibre-optic cable to buoys on the surface. Physical oceanographers need more power, which they have obtained by building observatories on subsea

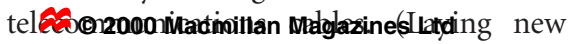
subsea cable over long distances is too expen- sive for researchers to contemplate.)

Researchers interested in the biology and chemistry of the ocean have been slower to use the permanent observatories, and the report says they still lack the sensor technology they need to do this.

\section{Black boxes}

But the migration of all of these branches of oceanography to observatory-based datagathering is inevitable, say the study's authors. Fisheries, pollution and everything else will be observed by little black boxes on the sea floor. "The bottom line is that our ideas and models for explaining phenomena may be stuck if we don't have new methods," says Ryan. "We may be kidding ourselves that intermittent lowering of instruments into the oceans is catching the right things. It is time to look at the oceans in a more rigorous way."

NOAA welcomed the report and expressed its willingness to participate in the network. Jim Baker, its administrator, says the NOAA, NSF and Navy are already discussing ideas for seafloor observatories through an existing forum, the National Oceanographic Partnership Program. He adds that the White House Office of Management and Budget "has left the door open" for an interagency proposal to start building the network next year.

But international collaboration may be a long way off. Several nations, including the United Kingdom and Japan, already have their own networks. "If we want this to happen in anyone's lifetime, the NSF should plan it now and work out international cooperation later," said an NRC study official. 